\section{ON THE PROBLEM OF GLYCOSURIA AND DIABETES. ${ }^{1}$}

By W. HALE WHITE, M.D., F.R.C.P. LoND., PHYSICIAN TO, AND LECTURER ON MEDICINE AT, GUY'S HOSPITAL.

WHEN I accepted the honour of an invitation to speak at this debate I never dreamed it would fall to my lot to open it. Had I done so I should not have dared to accept, for the subject is so vast and the difficulties are so great.

The first thing that naturally attracts our attention is the recognition of dextrose in the urine. The universally employed copper-reduction test is unsatisfactory. As an example I may mention that about 20 years ago, when the nervous theory for diabetes was in the ascendant, it was urged in support of it that the urine of lunatics frequently contained sugar. Dr. G. H. Savage and $\mathrm{I}^{2}$ showed that this was not so ; the mistake probably arose from confounding the reduction given by kreatin and the other reducing bodies in the urine with that given by sugar. We all know the difficulty in life insurance work of estimating the value of a dirty greenish-brown precipitate given by boiling urine with copper solution and an alkali. We have probably all come across people condemned as diabetic who are not and the mistake has arisen either from the use of a stale copper solution or because of an abundance of reducing bodies in the urine which are not sugar. Those who are alkaptonuric are usually condemned as diabetic. The polarimeter, fermentation, and the formation of osazone crystals are all excellent tests, but the first requires an expert, the second is tedious, and the third needs time; there may be delay in the formation of the crystals and glycuronic acid also gives crystals which, however, are in rosettes of thick plump needles, not bundles of long needles like those of phenyl-glucosazone. We want someone to get up and to tell us that he has found a test by which small quantities of dextrose can be detected in the urine as easily as small amounts of albumin. We also want to know more about the appearance of glycuronic acid ${ }^{3}$ in the urine. Do some people pass it and later become glycos. uric? One case I have seen suggests but does not prove that this may be so. A woman whom I saw ten years ago complained of thirst and dry skin; the urine had a low specific gravity (1008), contained no albumin, but gave on many occasions an abundant brick-red precipitate on boiling with Fehling's solation. It did not ferment. I saw her again a few weeks ago and she is now passing genuine sugar, but the urine does not give a ferric chloride reaction. Bearing on this we have Futcher's ${ }^{4}$ paper in which he shows that both fusel oil and tertiary amyl alcohol cause both dextrose and glycuronic acid to appear in the urine. Then, too, it appears that some sufferers from diabetes pass a little glycuronic acid, and it has even been stated that minute amounts of this acid may be found in healthy urine. Indeed, it must be remembered that there is every reason to believe that its appearance depends upon its being provided with something to combine with rather than on any disturbance of carbohydrate metabolism. Have any here present practical experience of Bial's ${ }^{5}$ test for it? There is, I think, no doubt that in most cases the presence of glycuronic acid is asserted on insufficient grounds. A copperreducing body is found which is not sugar and it is assumed to be glycuronic acid.

Allied to this is another subject on which we want further information-namely, that we occasionally see patients suffering from exophthalmic goitre who for a long while pass an abundance of sugar in the urine. For example, I saw a

1 Being the opening remarks at the debate on Diabetic and Nondiabetic Glycosuria at the Chelsea Clinical Suciety on March 10th, 1903.

p. 348 .

3 See a case by Ashdown, Brit. Mex. Jour., vol. i., 1890, p 167; also Bial, Ueber Bildung und Ausscheidung der Gly' uronsäure, Zeitsehrift für Klinische Medicin, Band xlvii., Hefte 5 and 6 .

4 Futcher : Fusel-oil Poisoning with Special Reference to the Copperreducing Substances eliminated in the Urine, American Medicine, August 10th, 1901.

5 Bial's reagent consists of orcin, concentrated hydrochloric acid, and ferric chloride, equal quantities of the reagent and of the urine being taken. On just raising to boiling pentose gives a green-hlue colour readily taken up by amyl alcohol and with a characteristic spectrum. If boiling is continued glycuronic acid gives the same reaction. patient ten years ago with marked exophthalmic goitre and glycosuria. Her medical attendant writes now to say that the glycosuria persisted for two years, slowly the symptoms of exophthalmic goitre have disappeared, and now she is "practically well." Some authors have maintained that glycosuria is particularly easily induced in patients with exophthalmic goitre, but von Schrötter ${ }^{6}$ gave such a patient grape sugar in doses of 200 grammes without any appearing in the urine. I have notes of one patient with exophthalmic goitre whose father had diabetes and of another who has two sisters who have diabetes. Probably the fact that polyuria, thirst, and great hunger are frequent symptoms met with in exophthalmic goitre is unconnected with the glycosuria, for they occur independently of it and in support of this is the fact that Dr. H. French, ${ }^{7}$ making observations on a patient of mine with severe traumatic diabetes insipidus, was unable to produce glycosuria even by giving large amounts of sugar.

We want information about the occurrence of other sugars than dextrose in the urine. Clinically, three appear to be important-lævulose, lactose, and pentose. Lævilose I will refer to presently. Can any speakers give us definite information about the after-history of women who during suckling pass lactose in their urine? It is stated that of those who develop glycosuria during pregnancy recovery takes place in three-quarters, with a tendency for the glycosuria to recur in other pregnancies, but we want to know of the quarter who do not recoverdo they become genuine diabetics or continue to pass lactose? Aiso, we want to know if a quarter is not too high a proportion of those who do not recover; probably it is. Tery few, if any, observations have been made in England on pentosuria. Pentose appears to exist in the urine in two conditions-namely, in association with other sugars in diabetes-as, for example, d'Amato has recently recorded the case of a patient with a pancreatic calculus and diabetes in whom the urine contained both dextrose and pentose-and in very rare cases as an independent condition in which although pentose appears in the urine the patient can utilise pentose. Brat ${ }^{8}$ has recently recorded a case of pentosuria in a woman, aged 62 years, whose brother also had pentosuria. Some of the patients with pentosuria were morphomaniacs. Is pentosuria found in any large proportion of morphia takers? In passing I should like to suggest that as accuracy of language leads to accuracy of thought we should when we know the sugar in the urine to be dextrose speak of dextrosuria, thus harmonising with lævulosuria, pentosuria, and lactosuria.

Talking of nomenclature leads me to ask for a more accurate use of the word diabetes. Even the use of the additional word mellitus does not help, for many speak of alimentary glycosuria as diabetes mellitus. As it is now, if I hear a patient has diabetes I do not know whether he has the comparatively harmless alimentary glycosuria or the dangerous disease diabetes in which he is liable to coma and passes oxybutyric acid and its derivatives in his urine. Fagge was of opinion that the word diabetes should be used only for the severer disease and this would be best; however, I doubt whether now this is possible, but at any rate we might adopt Dr. F. W. Pavy's excellent suggestion and speak of alimentary diabetes and $u$ se the phrase "composite diabetes" to indicate the patients who pass sugar and oxybutyric acid and its derivatives, of which aceto acetic acid is recognised by the ferric chloride reaction and acetone by the nitro-prusside of sodium reaction, but the detection of acetone is not nearly so important as the detection of aceto-acetic acid, for acetone is often present in persons who have no diabetes. It cannot be too strongly urged that no case of sugar in the urine has been even superficially examined unless the ferric chloride test has been employed.

We badly want a series of cases recorded with a view of finding out what proportion of these alimentary cases become composite cases. Some will certainly appear to do so, for many an apparent alimentary case is really the early stage of a composite case, indeed, Ebstein believes that this is so of all alimentary cases. Dr. Pavy, too, is strongly of opinion that alimentary cases often at least later become composite unless properly treated. Properly treated, however, a patient suffering from the alimentary

6 Zum Svmptomencomplex des Morbus Basedowii, Zeitschrift für Klinische Medicin, Band xlviii., Heft 1.

Guy's Hospital Reports, vol. lvii., p. 133

\& II. Brat: Beitrag zur Kenntniss der Pentosurie und der Pentosenreaction, Zeitschrift fiur Klinische Medicin, Band xlvii., Hefte 5 and 6 . 
form may remain perfectly well for many years. Three months ago I saw a man, aged 62 years, whose urine had a specific gravity of 1036 ; it contained much sugar, gave no ferric chloride reaction, and he appeared perlectly well. He said that sugar was detected in 1885 and that he had dieted carefully for the last ten years. Such a case as this casts doubt on the view that hyperglycæmia is harmful. It is true that many a patient with this form of glycosuria has a little albuminuria and rigid arteries, that he is liable to gangrene or boils, and that he bears operations and illnesses badly, but are not all these, like the glycosuria, to be regarded as evidence of structural and functional decay rather than as due to the glycosuria? However, it must be remembered that the passage of sugar being a loss of energy is in itself harmful, but as the amount of sugar is usually small this loss of energy is generally unimuortant. It is strongly in support of the above view that this form of g] $\mathrm{y}$ cosuria is met, with chiefly in elderly people. There is sometimes a tendency to treat these alimentary cases too severely. It is not necessary to reduce the carbohydrates in the food beyond the point that leads to their disappearance from the urine. But the urine should be more carefully examined than is usually the case, for an alimentary lævulosuria" has been described. A complete record of such a case, giving the effects of the administration of dextrose and lævulose, would be very valuable and we should like information as to the value of Seliwanoff's test for lævulose. ${ }^{10}$ To be strictly accurate we ought to speak of alimentary dextrosuria aid alimentary lavulosuria as the case may be. It will be noticed that I have assumed (what I believe to be true) that while many patients with so-called alimentary glycosuria are really in the early stages of composite diabetes, yet others are examples of a much less harmful condition which always remains alimentary glycosuria, never passes on to comporite diabetes, and lacks the serious metabolic phenomena of this disease. Whether this is so is a very fair subject for discussion.

The occurrence of sugar in the urine due to diseases or injuries of the nervous system is of little clinical interest. It is usually slight and transitory. If the nervous lesion causes coma and sugar is found in the urine the case may at first be mistaken for diabetic coma. I was called to a case not long ago in which this mistake had been made, but the failure to find either acetone or aceto-acetic acid in the urine showed the case to be one of nervous glycosuria. The patient died from cerebral hremorrhage and it was found that blood had passed down the iter in the fourth ventricle. Dr. A. P Beddard has kindly directed my attention to a similar case ${ }^{11}$ in which acetone chanced to be in the urine. Acetoacetic acid was not looked for, but doubtless ferric chloride would have shown its absence. Testing for the ferric chloride reaction will always prevent a mistake between a nervous lesion causing coma with sugar in the urine and diabetic coma.

We now pass on to consider diabetes proper or, as Dr. Pavy calls it, " composite diabetes." This may be defined as a disease in which dextrose is present in the blood and urine and in which, if the disease is untreated, ultimately lævo-rotary $\boldsymbol{B}$ hydroxybutyric acid appears in the blood and urine and the output of carbohydrates in the urine is greater than can be accounted for by those in the food. By far the most important sugar in the urine is dextrose, but small quantities of lævulose, pentose, combined glycuronic acid. and other closely allied bodies are sometimes present. We know that there is a great excess of sugar in the blood and that this excess is very largely due, and probably in many cases-at any rate, in the early stages-entirely due, to the failure of the body to utilise the sugar, but even in many severe cases the power to utilise sugar is not entirely lost But this is not in all cases the entire explanation of the presence of sugar in the blood, for in a severe case of diabetes there may be sugar in the blood and urine even if carbohydrates are entirely absent from the food. Such sugar must come either from proteids or fat and the prevailing opinion is that it comes from the proteids, for, in the first place. diabetics do very well on fat and, in the next place, only a little sugar conld be produced even from a large amount

\footnotetext{
9 Rosin and Laband: Ueber Spontane Lavulosurie und Lavulosämie, Zeitschrift fnr Klinische Medicin. Band x lvi. Ifefte 1 and 2 .

10 Seliwanoff s test is fully described in Rosin and Lihand's paper. It consists in a bright red colour given aftor heating an equal part of urine with fuming hyolrochloric acid and a little piece of resorcin This reaction is only given by sugars allied to ketones and therefore by lievulose. Acetone alt hough a ketone does not giveit. There is no other body than linvulose which ferments and gives this reaction.
}

of fat. ${ }^{12}$ But it is clear that even in a case in which sorne carbohydrate is present in the food we cannot tell whether some in the blood may not have been derived from the tissues if the patient has not completely lost his power of utilising ingested sugar.

The next point of interest is not nearly sufficientl grasped-namely, that many diabetics can utilise Jævulose much better than dextrose. Many observers have noted this and I have frequently observed it. It is said ${ }^{13}$ that a diabetic patient soon loses his power to utilise lævulose, but I know that he may retain it for a long while and by examining the urine we can soon see when he is losing his power. This ability to utilise lærulose suggests that experiments might be made to see whether diabetics can utilise other sugars-e.g., pentose.

I have read many articles on diabetes which contain no reference to the extraordinary fact that, as was pointed out by Dr. Pavy many years ago and which $I$ have often observed, a diabetic patient who is on strictly carbohydrate-free diet may, if a little carbohydrate is given, excrete far more sugar than that given. This is so important and so little known that I may be excused for quoting word for word from Dr. Pavy : " "The information supplied ...... goes to show that not only may starch and sugar ingested traverse the system unappropriated but that their ingestion may act in such a way upon the complaint as to give rise to the elimination of more sugar than could be derived from the principles themselves. Thus after sugar bad for some days been entirely absent from the urine under restriction to an animal regimen two ounces of ordinary bread per diem were for a couple of days allowed and then the restricted diet again resumed. During the first day that the bread was taken the patient passed 117 grains of sugar and during the second 196 grains. The following day he passed 213 grains, the next 571, then 236 grains, and la-tly 92 grains. After this there was an absence of sugar. By the four ounces of bread the elimination of 1425 grains of sugar was occasioned which is more than could be derived from the bread itself, for I found ...... the whole of the solid matter in the bread consumed only amounted to 1200 grains, against the 1425 grains of sugar discharged in the urine. Another point worthy of attention is that the elimination of sugar continued increasing for two days after the bread had been discontinued." Thus we see that the administration of sugar may act as a direct excitant of sugar formation in the body (presumably from proteid), and if in any case some of the sugar taken is utilised we have no means of knowing whether or not some of that in the urine is not derived from the tissues which have been excited to form sugar by the ingestion of carbohydrates. No explanation of the carbohydrate metabolism in diabetes will be satisfactory unless this fact is remembered.

Then, again, we want an explanation of the strange disappearance of sugar when coma comes on. This may be of great practical importance. Not long ago I saw with $\mathrm{Mr}$. E F. White of Putney a patient who was not known to have diabetes; she became comatose in the course of influenza and the first specimen of urine examined contained no sugar, but we were put on the right path by finding an abundance of aceto-acetic acid. Many years ago I tried giving one or two patients syrup, but it had no effect on the coma and they did not live long enough for us to determine whether there was an increased output of sugar.

We much need information as to why the body fails to utilise dextrose. It has not lost the general power to oxidise-it can use fats, lactates in a diabetic are oxidised to carbonates, and benzol is oxidised to phenol. The only explanation whirh is open to us appears to be that usually offered-namely, that before the sugar can be oxidised it has to be prepared in some way and the diabetic lacks the power to do this. Many symptoms - e g, polyuria, the bigh specific gravity of the urine, and pruritus vulvæ-can obviously be explained by the presence of sugar, but, as previously mentioned, $\mathbf{l}$ think many symptoms are ascribed to hyperglycamia on insufficient evicence; for instance, we are told 15 that these " results of hyperglycamia consist chiefly in a striking tendency to 12 Hesse: Ueher Eiweissumsatz und Zuckerausscheidung des
Schueren Diabetikers, Zeitschrift fur Klinische Medicin, Band xlv.,

Hefte 4 and 5 .

1:3 Socin : Wie verhalten sich Diabetiker, \&c. Dissert. Strassburg, (9)4 (guter by Bunge), Physiological and Pathological Chemistry second Inglish edition translated lo F. A. Starling

15 Edsall: Proceedings of the Pathological Societ y of Philadelphia Oct. 1st, 1901, p. 232. 
infection and necrosis of the tissues." This may or may not be so, but considering the many ways in which metabolism in diabetes is perverted it appears rash to ascribe these results to the sugar. It is almost impossible to resist the temptation of believing that the wasting is due to the loss of energy in the urinary sugar. Many diabetics lose 500 calories of energy a day in their urine and it is said that they attempt to make up for this by utilising their proteids and fats and hence they waste. But as Bunge points out, this is a teleological argument and I think most of us feel that teleological arguments are dangerous. It would be a valuable observation to record the weight and nitrogenous excretion of a diabetic kept on a weighed ordinary diet but absolutely at rest in bed and therefore not requiring the energy lost in the urinary sugar. As sugar is chielly consumed in the muscles it is supposed by some that the fault in diabetes lies in them and it has even been suggested that it is a good treatment for diabetics to do muscular work. Considering the loss of energy in the urinary sugar this hardly seems likely and it would be very valuable to have definite information.

In a debate on diabetes much attention must be given to the coma. It is even of greater importance than the glycosuria, for it is the commonest cause of death. At the present time the prevailing view is that the coma is in some way dependent upon the lævo-rotary $\beta$ hydroxybutyric acid which is found in the blood of a patient in diabetic coma. It is excreted in the urine and even as much as 119 grammes have been said to be excreted in a day. $\beta$ hydroxybutyric acid exists in three forms, ${ }^{16}$ as inactive, lævo-rotary, and dextrorotary ; in the body aceto-actic acid and acetone are formed from it and we usually infer its presence from finding one of these in the urine. The right-handed acid is more easily decomposed in the body than the left-handed which is the acid of diabetes. Two views prevail as to the way in which this acid acts to produce coma. One is that it or its precursor or its derivatives are directly toxic Sternberg claims to have produced symptoms like those of diabetic coma by administering $\beta$ amidobutyric acid which he regards as a precursor of $\beta$ hydroxybutyric acid, but it must be remembered, as Magnus-Levy ${ }^{17}$ points out, and n't the beta group and, further, I do not think that the animals which were poisoned with $\boldsymbol{\beta}$ amidobutyric acid by either Sternberg or Grube appear from the written description to have had symptoms very like diabetic coma. Nor have these symptoms been satisfactorily produced by the administration of hydroxybutyric acid, aceto-acetic acid, or acetone, and, further, these bodies may be present without diabetic coma. The other view is that the hydroxybutyric acid, acting merely as an acid, diminishes the alkalinity of the blood, neutralising its sodium phosphate and carbonate, and hence the acid interferes with its power as a carrier of carbon dioxide, and the carbon dioxide consequently retained in the tissues is supposed to be the cause of the coma. About two facts there is no doubt. First, there is much oxybutyric acid in the blood and its alkalinity is much reduced. By distilling the urine with strong sulphuric acid crotonic acid is formed if oxybutyric acid is pre-ent; the presence of the acid has been in this way demonstrated by various observers and also in the last two cases of diabetes under my care. In both these, as many have found in other cases, the ammonia excreted in the urine was excessive and Herter ${ }^{i 8}$ points out that the calcium and other bases in the urine are much increased when oxybutyric acid is pre-ent, showing that the lessened alkalinity of the blood has led to the calling forth of these bases from the tissues, and bv estimating the ammonia and other bases in the urine he believes we can approximately learn the quantity of "ixubutyric acid in the $b^{\prime}$ ood. As aceto-acetic acid is a derivttive of oxybutyric acid we u-ually roughly infer its presence by the ferric chloride reaction. Secondly, there is no dnubt that the carbon dioxide content, of diabetic blood is abn irmalle low, as shown for example by Kraus. ${ }^{19}$ My friend Dr. E. I. Soriggs has kindly allowed me to give some results which he has obtained in the physioBeddard and Dr. M. Pembrey. The gas estimations

18 VeKenzie: The Resolution of $\boldsymbol{\beta} \mathrm{Hvdroxyhntyric} \mathrm{Acid,} \mathrm{\& c.,} \mathrm{Journal}$ of the Chemical Society. Novemher, 19n2, p. 1402.

17 Migmus-Levy : Archiv fur Fx perimentelle Pathologie und Pharmakologie, Band xlv. Hefte 5 and 6 .

19 Lubarsch und Ostertages Ergebnisse, \&c., 1895, Band ii. of the blood from cases of diabetic coma gave from 14 to 23 volumes of carbon dioxide in 100 grammes of blood instead of from 40 to 50 , the figures found for normal venous blood. The alkalinity of the serum varied from 0.04 gramme of sodium hydrate per cent. to 0.06 , the normal being from 0.1 to 0.15 . The blood of two diabetics who were not comatose was examined and it contained 24 and 33 volumes of carbon dioxide, so it was less than normal but not so much less as in the comatose cases. The carbon dioxide content of the urine, too, was diminished. But it has always seemed to me a far cry to argue that because there is little carbon dioxide in the blood therefore it is retained in the tissues, for blood could probably carry away in simple solution enough carbon dioxide to prevent toxæmia of the tissues by carbon dioxide, and this is quite supported by what Dr. Spriggs tells me, for he and his fellow experimenters found that blood from a case of diabetes can absorb carbon dioxide about as well as ordinary blood; thus on passing carbon dioxide through diabetic blood it took up from 200 to 300 volumes per cent. of carbon dioxide. This appears to show that the lack of carbon dioxide in the blood is not due to inability of the blood to take it up but may be owing to a low tension of carbon dioxide in the tissues in diabetes and especially in diabetic coma. Therefore it appears that in diabetes there is a poison which has two effects-namely, the production of coma and the lessening of the carbon dioxide in the tissues. What this poison is we do not know. That it merely acts as an acid is, I think, judging from experiments doubtful, but there is considerable evidence that it is closely associated in some way with oxybutyric acid (although, as already mentioned, it is very doubtful if oxybutyric acid itself, its known derivatives, or amidobutyric acid are the poison), for oxybutyric acid is always abundantly present both before and even more during coma. ${ }^{20}$ This view, that the poison is in some way closely allied to oxybutyric acid, is strongly supported by the fact that sometimes coma is benefited by giving alkalies. I have seen distinct benefit follow and Magnus-Levy records an excellent case, but as this treatment in no way destroys the poison or prevents its formation, at best only neutralising its acid properties, we must expect it often to fail, as, indeed, it does. It is interesting in this connexion to learn that Dr. Spriggs did not find that the injection of alkalies increased the carbon dioxide content of the blood in two fatal cases of diabetic coma, which is what we should expect if we are right in believing that the carbon dioxide in the tissues is far below normal. I might in passing add that he found that in the last stages the administration of alkalies did not diminish the proportion of ammonia in the urine.

Much discussion has taken place as to the origin of the 8 oxybutyric acid It does not come from carbohydrates, for it may be present when they are withheld from the food and are absent from the urine. Until recently it was thought to come from proteids, now some suggest it is derived from fats, and again Magnus-Levy suggests that it is formed by breaking down of both fats and proteids. ${ }^{21}$ If it does come from proteids the metabolism which leads to it is probably different from that leading to sugar, for a strong ferric chloride reaction may be present in the urine even after sugar has quite disappeared. I bave noticed this in children and if oxybutyric acid is derived from proteid we learn that, at any rate, not the whole of the abnormal proteid metabolism is to compensate for loss of energy in urinary sugar. Until we know the source of oxybutyric acid we shall probably not know how to avoid coma. Grube ${ }^{22}$ believes it is likely to appear if butter is taken but not after pork. This hardly seems likely, considering how well diabetics take butter. There seems no doubt that casts often appear in the urine in enormous numbers, especially before coma. It will be of great interest if we can learn something of their origin and prognostic value.

The sugar and oxybutyric acid in the urine are not the only evidences of perverted metabolism, for sometimes the blood is of a peculiar salmon or strawberry-and-cream colour, a fact quite ignored by many who write on diabetics. Usually the blood is said to be fatty. Some analyses have shown a considerable amount of fat and in some of the published

20 Herter : Acid Intoxication of Diabetes in its Relation to Prognosis, Journal of Experimental Medicine, vol. v., No. 6, 1901. Magnus-Levy, op. cit.

21 Op. cit. 22 Grube: Zeitschrift fur Diätetische und Fhysikalische Therepie,
Band vi., Heft 2 . 
cases $^{23}$ globules stained with osmic acid were present, but even then there was a quantity of granular matter, and a case I have been recently studying and which $I$ hope soon to publish seems to show that the blood may be of quite a pale strawberry-and-cream colour and yet contain no fat staining with osmic acid but a quantity of granules which appear to be proteid precipitated by the presence of an ester of cholesterin with one of the fatty acids. The altered colour of the blood may be easily visible in the retinal arteries and it may slowly pass away as the patient improves.

Turning to the morbid anatomy of composite diabetes we know that the brain, spinal cord, and nerves show no nakedeye or histological changes sufficiently often for such to be regarded as the cause of diabetes. I have frequently examined these and the sympathetic ganglia with negative results. ${ }^{24}$ But speaking of the nervous system reminds us that the explanation of the fact that the knee-jerk is absent in 50 per cent. of diabetics is difficult considering how rare other symptoms of neuritis are. There are often striking changes in the pancreas. During 14 years at Guy's Hospital out of 6702 necropsies the pancreas was diseased to the naked eye in $142^{25}$ and in 19 of these the diseased pancreas was associated with diabetes. An examination of all the fatal cases of diabetes showed that in a quarter naked-eye disease of the pancreas was present. In 16 out of the 19 the gland was much atrophied, shrunken, and indurated, and this is, I think, the typical pancreas of diabetes; of the remaining three in one the gland was atrophied as a result of a pancreatic calculus and in one it was large and indurated. Hausemann analysing the figures at the Berlin Pathological Institute found in ten years disease of the panereas with diabetes 40 times and of these cases in 36 the gland was atrophied. There appears no doubt that destruction of the islands of Langerhans is of great importance in connexion with diabetes. A co!lection of cases by Steele ${ }^{26}$ which has been recently published shows this. Of course, it is well known that diseases which only partially destroy the pancreas do not cause diabetes. Three points on which we want information in this debate are-(1) is alteration in the islands of Langerhans the essential feature of the pancreatic disease which causes diabetes? (2) can we during life tell which cases have and which have not pancreatic disease? and (3) what is the relationship of the internal pancreatic secretion to diabetes?

Passing to the subject of treatment I need not urge the advantages of withholding carbohydrates from the food, for by doing so the patient gains strength and weight; and the excretion of sugar and oxybutyric acid diminishes at any rate in most cases, but sometimes $I$ have obtained an intense ferric chloride reaction even after weeks of strict diet and even when the sugar has disappeared from the urine. It often seems to me that in many cases dieting has been too strict and as a rule there is at any rate no harm in milk. In any case I would suggest that when diet will not completely control the glycosuria the patient should be allowed just so much carbohydrate as will not increase the sugar in the urine and when diet will control it he should be allowed carbohydrate food up to just below the point at which it leads to glycosuria. Lævulose is certainly the best carbohydrate; it may be given up to any quantity so long as it does not cause or increace the glycosuria. Inulin, which is the starch corresponding to lævulose, may also be given; it occurs in dahlia tubers and these may be cooked and eaten like potatoes. There is a pernicious belief among some patients that toast may be taken instead of bread. I need hardly say that this is not so. Although there are many reasons against alcohol yet in a severe case advan. tage may be taken of its energy-yielding power provided it is unsweetened. Many cases are probably not allowed enough fat. We should all be agreed that too sudden a deprivation of carbohydrates may lead to coma, but why this is we do not know, nor do we understand the undoubted and very important fact that coma is often brought on by exertion, worry, or mental anxiety. Unfortunately we are much in the dark as to the treatment of coma. As is shown by cases recorded by Fagge, the injection of normal saline solution will sometimes bring the patient out of coma, but he relapses again in a few minutes. Better still is the use of large quantities of alkali. If a pat;ent feels a little drow:y it is a good thing to order 100 grains of bicarbonate

23 Sanders and Hamilton : Edinburgh Medical Journal, July, 1879. Diseases of the Sympathetic, Guy's Hospital Reports, vol. xlvi. $20^{\circ}$ American Journal of the Medical Sciences, July, 1902, p. 71 of sodium or 50 of the carbonate dissolved in a pint of milk and for him to drink three or four such pints in the 24 hours. If the coma is deeper a solution of sodium bicarbonate may be injected subcutaneously, so that at least 200 grains are given at the first injection, or $I$ have given it per rectum, but that is much less certain. If the case is at all severe, with an abundant ferric chloride reaction but no coma, I am accustomed to order some 50 to 100 grains of bicarbonate of sodium to be dissolved in milk and taken during the day. From cases I have watched I am certain that this treatment is useful and I think that it sometimes tides over a time till the good effect of dietetic treatment is felt. It often fails to save life, but then we must remember that it does not stop the formation of the poison. It is evidence in support of this view that diabetics often appear to derive much benefit from alkaline waters. The bowels of these patients should be kept well open, for by that means we may eliminate some of the poison; possibly the abdominal pain and vomiting which so often herald coma should be interpreted as an attempt to rid the body of the poison by way of the gastro-intestinal tract. There appears to be no doubt that both morphia and codeine can diminish the excretion of sugar; it will be of interest to hear why they are used less than they were. Aspirin is said to act beneficially in some cases, and I hope we may have some evidence for or against it. Dr. A. F. Garrod told me of a child, aged seven years, who on fixed diet was excreting 30 grammes of sugar a day; she was put on 15 grains of aspirin a day and the excretion of sugar fell, varying from six to ten grammes. After a week the aspirin was stopped and the excretion of sugar fell to two or three grammes a day. It must be remembered that aspirin, being a salicylate, will itself give a ferric chloride reaction. I have tried feeding diabetics on pancreas ${ }^{27}$ and have injected liquor pancreaticus subcutaneously but without success, nor does the use of Professor Starling's secretin appear to be beneficial. 'The treatment of the many associated conditions is beyond the scope of these remarks, but $\mathrm{I}$ cannot resist asking whether the number of cases of diabetic phthisis has not diminished of late years. I think that it will be found that it has.

The last point to which I would direct attention is whether we are not under the word "diabetes" really describing more than one disease ; for example, are some cases due to disease of the pancreas and some not? are those that have so-called fatty blood different from those that have not? are those in which glycogen is present in the liver different from those in which it is absent? In. conclusion, I need hardly say I am well aware that in these few remarks many points of great interest have not been touched upon, but as the subject is so extensive $I$ have confined myself to indicating, although very imperfectly, those which appear in the present state of our knowledge to be the more important.

\section{THE USE OF SALICYLIC ACID AS A PRE- SERVATIVE IN FOOD.}

By C. J. MACALISTER, M.D. EdIN., M.R.C.P. Lond., PHYSICIAN TO THE ROYAI SOUTHERN HOSPITAL, LIVERPOOL, ETC.; AND

T. R. BRADSHAW, B.A., M.D. DUB., M.R.C.P. LOND., PHYSTCTAN TO THE ROYAL INFIRMARY; LECTURER ON CLINICAL MEDIOINE IN UNIVERSITY COLLEGE, LIVERPOOL, ETC.

IN the course of the past two years our opinions have been sought with reference to the harmfulness or otherwise of the ingestion of small amounts of salicylic acid for prolonged periods and we have consequently been interested in making a careful investigation as to the effects produced by this substance, especially upon the nutrition and upon the digestive processes of the economy ; for it is mainly upon these that injurious effects are said to have been exerted. We have been the more interested in our endeavours to gain information upon this matter because it has been evident to us that some industries have suffered considerably by the exclusion of salicylic acid as a preservative from their

27 Brit. Med. Jour.. March 4th, 1893 1902.

A paper read before the Li. erpool Medical Institution on Nov. 20th, 